\title{
Impressão 3D de milirreatores com defletores triangulares para fermentação alcoólica do suco de uva
}

\section{Alan C. Rodrigues*, Adriano G. P. Silva, Osvaldir P. Taranto e Harrson Silva Santana}

\section{Resumo}

Este trabalho tem como objetivo avaliar a impressão 3D de milirreatores com micromisturadores com defletores triangulares e verificar a viabilidade dos mesmos para realizar fermentação alcoólica. Foi feito um estudo de imprimir os dispositivos com o canal em forma de um pentágono com base retangular, analisando variáveis de impressão e vazamento dos dispositivos, obtendo melhor resultado em relação aos canais retangulares (utilizados em estudos anteriores). Em seguida testou-se o milirreator com $2120 \mathrm{~mm}$ de comprimento de canal, $5 \mathrm{~mm}$ de largura e $3 \mathrm{~mm}$ de altura para a reação de fermentação alcoólica de suco de uva, obtendo um rendimento de $14,27 \%$ e uma concentração de etanol de 2,02 g L-1 para um tempo de residência de 4 minutos.

\section{Palavras-chave:}

millireatores, fermentação alcoólica, impressão 3D.

\section{Introdução}

Algumas pesquisas na área de escalonamento têm revelado algumas estratégias interessantes de como realizar um aumento na produção utilizando microdispositivos, dentre elas tem-se a scale-out by suitable dimension enlarging. Essa estratégia diz que o tamanho do canal do microdispositivo pode ser elevado para uma escala suficientemente grande a fim de alcançar o rendimento desejado. No entanto, é fundamental manter as vantagens de uma mistura rápida, elevada transferência de calor e massa otimizada na microescala. Diante disso, este trabalho pretende avaliar de maneira experimental um micromisturador com defletores triangular (MTB), desenvolvido pelo grupo, em processos químicos, visto que os ensaios numéricos mostraram uma elevada eficiência de mistura e é esperado que seja possível, experimentalmente, obter elevados rendimentos reacionais em baixos tempos de residência.

\section{Resultados e Discussão}

Primeiramente foi realizado um estudo para verificar a maneira de projetar os desenhos 3D para impressão dos milirreatores, devido a complexidade do formato dos desenhos dos canais e, também, para evitar o vazamento. Com base nesse estudo, foi utilizado para impressão um canal pentágono de base retangular (vide Figura 1a) que facilita a impressão do topo do canal evitando camada inteiras sem base de sustentação, o que diminuiu significativamente os vazamentos dos canais nos testes realizados com até $20 \mathrm{~mL}$ min-1 de $^{-1}$ vazão de água por $10 \mathrm{~min}$. A Figura $1 \mathrm{~b}$ apresenta um canal impresso em 3D.

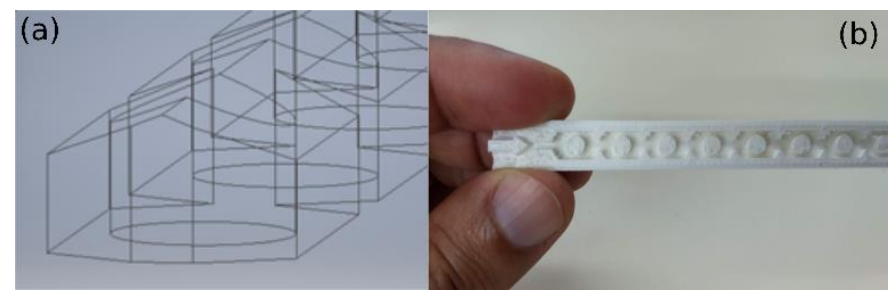

Figura 1.(a) Desenho de um milidispositivo MTB feito via Autodesk Inventor com formato de canal pentagonal com base retangular e (b) canais com micromisturadores com defletores triangulares fabricados em impressão 3D.
Com os resultados obtidos, um milirreator com MTB de 3 canais de $147 \mathrm{~mm}$ de comprimento $(\sim 450 \mathrm{~mm}$ de comprimento total), $3 \mathrm{~mm}$ de altura e $5 \mathrm{~mm}$ de largura foi testado para verificar o rendimento da reação de fermentação alcoólica do suco de uva. Foram utilizadas leveduras (Saccharomyces cereviciae) secas e ativas (Blastocel FR 95).

Foi obtido um rendimento abaixo de $5 \%$ com tempo de residência de $1 \mathrm{~min}$, podendo ser verificado que o tempo de residência tem grande influência no rendimento reacional.

Após os resultados obtidos foi desenvolvido um milirreator que permitisse maiores tempos de residência, sendo o novo milirreator MTB com 11 canais de $193 \mathrm{~mm}$ de comprimento de canal $(\sim 2120 \mathrm{~mm}$ de comprimento total) altura de $3 \mathrm{~mm}$ e largura de $5 \mathrm{~mm}$. Nesse milirreator foram avaliados tempos de residência de 1-4 min. Os resultados podem ser vistos na Tabela 1.

Dos resultados obtidos, verificou-se que em um tempo de residência de 4 minutos, o rendimento obtido se torna cerca de 3 vezes maior que reduzidos tempos de residência (1 $\mathrm{min})$.

Tabela 1. Efeito do tempo de residência no rendimento da reação de fermentação alcoólica. (Razão de corrente de levedura $20 \%$ em relação a corrente de suco de uva)

\begin{tabular}{ccc}
\hline $\begin{array}{c}\text { Tempo de } \\
\text { residência (min) }\end{array}$ & $\begin{array}{c}\text { Conc. de Etanol } \\
(\mathbf{g ~ L}-1)\end{array}$ & $\begin{array}{c}\text { Rendimento } \\
(\%)\end{array}$ \\
\hline 1 & 0,890 & 4,300 \\
2 & 0,802 & 3,605 \\
3 & 0,847 & 5,183 \\
4 & 2,022 & 14,273 \\
\hline
\end{tabular}

\section{Conclusões}

Nesse estudo foi apresentado um milirreator impresso em 3D com micromisturadores com defletores triangulares (MTB). Para testar a eficiência desse milirreator, este foi aplicado na fermentação alcoólica do suco de uva. O milirreator MTB apresentou um valor de rendimento de $14,27 \%$ e concentração de etanol de 2,02 $\mathrm{g} \mathrm{L}-1$ para um de tempo de residência 4 min.

FAPESP, CAPES, CNPQ.

Agradecimentos 